\title{
Signals of intensification and attenuation in orchestra and choir conduction
}

\author{
Isabella Poggi \\ Dipartimento di Filosofia, Comunicazione e Spettacolo \\ Università Roma Tre
}

Abstract:

Based on a model of communication according to which not only words but also body signals constitute lexicons (Poggi, 2007), the study presented aimes at building a lexicon of conductors' multimodal behaviours requesting intensification and attenuation of sound intensity. In a corpus of concerts and rehearsals, the conductors' body signals requesting to play or sing forte, piano, crescendo, diminuendo were analysed through an annotation scheme describing the body signals, their meanings, and their semiotic devices: generic codified (the same as in everyday language); specific codified (shared with laypeople but with specific meanings in conduction); direct iconic, (resemblance between visual and acoustic modality); indirect iconic, (evoking the technical movement by connected movements or emotion expressions). The work outlines a lexicon of the conductors' signals that in gesture, head, face, gaze, posture, body convey attenuation and intensification in music.

KEYWORDS: Music, conductor, gestures, multimodal communication, intensification, attenuation, intensity, dynamic indications

\section{INTENSITY}

Intensity in Linguistics is considered on the semantic side as a phenomenon of modification of the qualities and quantities within an utterance (Peruzzi, 2006), and on the pragmatic side as a modification of the illocutionary force by attenuating or strengthening it (Bazzanella \& Gili Fivela, 2009).

Thus, talking about attenuation and intensification in this domain means referring to phonetic, phonological, morphological, lexical, syntactic, textual, and rhetorical means which communicate that the level of a certain quantity or intensity is either lower or higher than expected, on behalf of pragmatic uses such as mitigation or other rhetorical functions. 
Adverbs such as English less, not so, slightly, for instance, or strongly, highly, more, Italian meno, leggermente, molto, tremendamente; but also affixes like English -let, hyper, Italian -ino, -one, micro, super- may be used to raise or lower quantities, and thus possibly also the importance or seriousness of the mentioned events. For example, a doctor telling the patient: "Le dò questo sciroppino" (I'll give you this little syrup) not only lowers the "status" of the prescribed drug, but also attenuates the seriousness of the patient's disease, possibly reassuring her (Caffi, 1991).

The same meanings of intensification and attenuation can be conveyed by hand, head, face, gaze and body signals: to intensify a sentence or an adjective in a way comparable to what adverbs like very do, one may shake head (Kendon, 2002) or squint eyes, or perform both actions at the same time (Vincze \& Poggi, submitted); a batonic gesture or a frown (Ekman and Friesen, 1969; Ekman, 1979; Poggi, 2007) with their meaning of giving emphasis, may result in intensification of the concomitant words. On the other side, an oscillating or rounding gesture expressing vagueness (Vincze et al., 2011), a grimace of doubt may convey attenuation.

In such cases the speech acts modified by these signals of intensification and attenuation are generally of an informative kind.

But intensity or quantity may not only be the object of informative speech acts or body communicative acts: they can also be the object of requests, for instance when a teacher asks pupils not to speak so loud, when you ask a very generous host to serve you less food in your plate, or when a stranger asks you to slow down your high speech rate. Another type of requestive signals of attenuation and intensification are ones performed in a peculiar communicative situation: gestures and other body signals performed by a conductor during musical performance.

The conductor's communication is a multimodal and multifunctional behavior in which words, gestures, face, posture, gaze, in both concert and rehearsal, provide information about the sound to perform: who should sing or play, when, and how; what semantic content to express by words and music, what melody, rhythm, tempo, timbre, intensity, expression, what musical structure to produce (Ashley 2000; Poggi, 2011).

Information about the intensity of the music being sung or played - its dynamic indications - is a relevant part of the conductor's job: s/he must often request musicians to play soft or loud ("piano" or "forte"), softer and softer ("diminuendo") or louder and louder ("crescendo"), that is, to increase or lower the acoustic intensity of their music; and the conductor does so mainly through communicative acts performed by hands, gaze, head, body movements.

This work presents an observational study aimed at analysing the body signals for intensification and attenuation in choir and orchestra conduction: in particular it focuses on the signals through which conductors request musicians to play or sing piano, forte, crescendo, diminuendo. The final aim is to write down a lexicon of these body signals of intensification and attenuation, while singling out their analogies and differences from ones used in everyday life, and finding out their semiotic mechanisms of construction.

\section{BODY MOVEMENTS IN MUSIC PERFORMANCE. A SHARED LEXICON?}

Previous works have argued that the signals used during musical performance are not totally idiosyncratic but rather systematic and shared. Concerning a Pianist's body 
movements, a "lexicon" was outlined (Poggi, 2006), i.e., a list of systematic correspondences between signals and meanings. Among a Pianist's body movement, some are definitely communicative, and we can attribute a performative and a content to each of them; some are expressions of cognitive states such as, for instance, concentration, or attention aimed at better listening to the tunes played; others are emotional states felt about playing (for example satisfaction or worry) or to be conveyed in music (sadness, mirth, grief). Others body movements, by accompanying the technical movement needed to produce a particular sound, tymber, rhythm, intensity, "help" the pianist to perform it better: for example frowning, being an expression of anger, by evoking anger mobilizes energy, thus helping the Pianist to play "forte". And as shown in that work, the same movements of trunk, gaze, head and face recurrently do have the same goal or convey the same meaning both across different passages in a music piece, and across concert and rehearsal.

If body signals are so systematic in the individual "lexicon" of a musician who generally plays alone, they must be even more so in the conductor, whose signals do not only have an expressive function but a communicative one (Poggi, 2011): if the conductor must convey to musicians what, when, and how to sing or play, then his signals must necessarily be shared, and form a common lexicon which allows a Japanese conductor to be understood by a German or an Italian orchestra.

\section{THE LEXICON OF ATTENUATION AND INTENSIFICATION IN ORCHESTRA AND CHOIR CONDUCTION}

Starting from the hypothesis that a lexicon of signals in music conduction can be outlined, within the above parameters of music about which the conductor must communicate to musicians (melody, rhythm, tempo, timbre, intensity, expression, musical structure), here I specifically focus on the parameter of musical intensity, in particular on the dynamic indications for forte, piano, crescendo, diminuendo - that are called dynamic indications in music - and I wonder what are the body movements conveying those requests.

To do so, I conducted an observational qualitative study aimed to analyse the signals of sound attenuation and intensification performed by orchestra and choir conductors.

\subsection{Corpus, method and hypotheses}

Ten fragments of orchestra and choir conduction by three different Conductors were analysed: two fragments taken from rehearsals by Riccardo Muti and Leonard Bernstein, on YouTube, and eight fragments (4 from concerts and 4 from rehearsals) by Alessandro Anniballi, the Conductor of an amateur choir in Rome. All in all, the analysed fragments last 122 '35", more specifically 27 ' 55 " of concert and 94' 40 " of rehearsal, respectively, and they were analysed through the annotation scheme in Table 1.

Table 1. An annotation scheme for signals of intensity

\begin{tabular}{|c|c|c|c|c|c|c|c|c|}
\hline $\begin{array}{l}1 . \\
\text { Time }\end{array}$ & $\begin{array}{l}2 . \\
\text { score }\end{array}$ & $\begin{array}{l}3 . \\
\text { words }\end{array}$ & $\begin{array}{l}4 . \\
\text { modality }\end{array}$ & $\begin{array}{l}5 . \\
\text { Signal } \\
\text { description }\end{array}$ & $\begin{array}{l}6 . \\
\text { Originary } \\
\text { meaning }\end{array}$ & $\begin{array}{l}7 . \\
\text { meaning }\end{array}$ & $\begin{array}{l}8 . \\
\text { Signal } \\
\text { type } \\
\end{array}$ & $\begin{array}{l}9 . \\
\text { Semiotic device }\end{array}$ \\
\hline \multirow[t]{2}{*}{3.18} & $\begin{array}{l}\text { Più } \\
\text { piano }\end{array}$ & $\begin{array}{l}\text { Je-e-su- } \\
\text { u Chri-i-i- } \\
\text { ste }\end{array}$ & posture & $\begin{array}{l}\text { Bust forward, } \\
\text { shoulders } \\
\text { closed, head } \\
\text { forward } \\
\text { downward }\end{array}$ & $\begin{array}{l}\text { make } \\
\text { myself } \\
\text { smaller } \rightarrow\end{array}$ & Softer & Iconic & $\begin{array}{l}\text { Transmodal iconicity: } \\
\text { space } \rightarrow \text { sound } \\
\text { Take less room = } \\
\text { make softer sound }\end{array}$ \\
\hline & & & gesture & $\begin{array}{l}\text { Elbows folded } \\
\text { Rh. Open, } \\
\text { palm down, }\end{array}$ & $\begin{array}{l}\text { refrain from } \\
\rightarrow\end{array}$ & $\begin{array}{l}\text { please } \\
\text { quiet } \\
\text { attenuat } \\
\text { e }\end{array}$ & $\begin{array}{l}\text { Symbolic } \\
\text { gesture }\end{array}$ & $\begin{array}{l}\text { Generic Codified } \\
\text { Transmodal } \\
\text { space } \rightarrow \text { sound }\end{array}$ \\
\hline
\end{tabular}


Signals of intensification and attenuation in orchestra and choir conduction | Isabella Poggi

\begin{tabular}{|c|c|c|c|c|c|c|c|c|}
\hline & & & & $\begin{array}{l}\text { pats } \\
\text { downward } \\
\text { Lh. palm } \\
\text { forward, move } \\
\text { backward } \\
\text { Lh. open } \\
\text { spread fingers } \\
\text { perp.to palm, } \\
\text { makes } \\
\text { precision grip }\end{array}$ & $\begin{array}{l}\text { I pick up } \\
\text { something } \\
\text { carefully }\end{array}$ & $\begin{array}{l}\text { be } \\
\text { careful: } \\
\text { do } \\
\text { somethin } \\
\text { g } \\
\text { subtle }\end{array}$ & $\begin{array}{l}\text { Iconic } \\
\text { spatiogr } \\
\text { aphic } \\
\text { gesture } \\
\text { Iconic } \\
\text { spatiogr } \\
\text { aphic } \\
\text { gesture }\end{array}$ & $\begin{array}{l}\text { Take less room = } \\
\text { make softer sound } \\
\text { Transmodal } \\
\text { Movement } \rightarrow \text { sound } \\
\text { Smaller grip = softer } \\
\text { sound }\end{array}$ \\
\hline & & & face & $\begin{array}{l}\text { Head forward, } \\
\text { tense lips }\end{array}$ & & $\begin{array}{l}\text { I ask for } \\
\text { attention } \\
\text { Be } \\
\text { careful }\end{array}$ & & \\
\hline & & & gaze & $\begin{array}{l}\text { Eyebrows } \\
\text { raised } \\
\text { Eyelids tense, } \\
\text { squeezed half- } \\
\text { closed }\end{array}$ & $\begin{array}{l}\text { I try not to be } \\
\text { heavy }\end{array}$ & Be light, & $\begin{array}{l}\text { Indirect } \\
\text { iconic }\end{array}$ & Help Movement \\
\hline
\end{tabular}

In this annotation scheme, the conductor's body signals which solicit dynamic action are analysed in detail: col. 1 contains the time in the video, col. 2 the dynamic indication written on the musical score, 3 (in case of choir performance) the words sung at the same time of the analysed conductor's signal; 4, the modality under analysis; 5, a description of the analysed signal in terms of its parameters: for instance, in Table 1 the Conductor's posture is described as "Bust forward, shoulders closed, head forward downward"; Col. 6 contains the goal of the body movement performed, which counts as its "originary meaning" - that is, the goal of the movement that counts as the "bodily" meaning, and from which the communicative meaning stems (Poggi, 2007): in this example, for instance, the posture is that of someone making himself smaller. Col. 7 contains the meaning conveyed by the movement described in col.5: in this case a posture of curling onto oneself to get smaller means "softer", i.e., "make a 'smaller' sound". Col 8. classifies the signal and col.9 its underlying semiotic device. For instance, making oneself smaller is an iconic gesture (col. 8) that exploits a transmodal shift (col. 9), from space to sound: a smaller body is similar to a smaller (i.e., softer) music; a body that takes less room recalls a sound that takes less energy.

Based on this analysis, the cases were singled out in which the same signals or aspects of signals systematically convey the same meanings throughout music performance. For each of the four meanings, "forte", "piano", "crescendo", "diminuendo", a hypothesis was put forward about the possible corresponding body signals performed by hands, face, gaze and posture. For example, a hypothesis was that index finger upward over lips - a symbolic gesture for "silence" - typically asks for "piano"; a high level of muscular tension generally asks for "forte".

The method employed to test each of the hypotheses put forward as to the meaning of the conductor's signals was devised on the basis of the following considerations.

In rendering the intensity of a music that is not performed as an improvisation, three intensities should be taken into account: 1) the dynamic indication written on the score, 2) the indication conveyed by the conductor through his body movements, and 3) the level of intensity actually performed by musicians. Our presupposition is that only in case of very novice musicians can their performance be very different from the conductor's indication; and in any case, their actual performance tells us how it was interpreted. 
Based on such reflections, the following method was adopted: first, with videos in mute mode, audio off, a careful analysis was carried of the conductor's communicative body movements through the annotation scheme above, and his dynamic indications were singled out; second, for each of these signals a hypothesis was put forward about its meaning - whether "forte", "crescendo", "piano", "diminuendo"; third, with audio turned on, it was verified if the corresponding sound confirmed the hypothesis; fourth, the same test was performed by looking at the score of the music played, to check if the dynamic indication at that time was really "piano", "forte", "crescendo", or "diminuendo" accordingly.

\subsection{Results}

The analysis resulted in a tentative lexicon of signals for intensity: a list of signals-meaning pairs in which the signal is a body movement and the meaning is an indication of intensity.

Table 1 presents the distribution of intensification and attenuation signals across modalities: gesture, head, face, gaze, body, posture, and voice. From a quantative point of view, the signals for intensification resulted to be more frequent than ones for attenuation: respectively, 50 signals for "forte" and 8 for "crescendo", 34 for "piano" and 7 for "diminuendo".

\begin{tabular}{|l|l|l|l|l|l|}
\hline & Forte & Piano & $\begin{array}{l}\text { Crescen } \\
\text { do }\end{array}$ & $\begin{array}{l}\text { Diminuend } \\
\text { o }\end{array}$ & TOT. \\
\hline Gesture & 33 & 23 & 5 & 2 & 63 \\
\hline Head & 3 & & & 1 & 4 \\
\hline Face & 5 & 1 & & & 6 \\
\hline Gaze & 7 & 7 & & 1 & 15 \\
\hline Posture & & 3 & & 1 & 4 \\
\hline body & 2 & & 3 & 1 & 6 \\
\hline Voice & & 1 & & 1 & 2 \\
\hline TOT. & 50 & 35 & 8 & 7 & 100 \\
\hline
\end{tabular}

Table 1. Signals of intensification and attenuation in various modalities

In the following we illustrate the gestural signals in some depth, finally giving a sketch about signals by head, face, gaze, voice, body and posture.

\section{GESTURES OF INTENSIFICATION AND ATTENUATION IN CONDUCTING}

Out of all the signals of intensity performed in all modalities, the gestural ones, that is, intensity indications performed by hands, arms and shoulders, are 63 in total; but since some of them are repeated more than once, out of all these tokens of gestures 21 gesture types can be singled out. Before listing all the types found (in Section 4.2), Section 4.1. overviews the semiotic devices that are responsibile for the creation of these gestures.

\subsection{Semiotic devices in gestures for musical intensity}

The gestures for intensity found in the above corpus can be distinguished in terms of the semiotic mechanisms that generated them. Five types can be listed:

1) generic symbolic gesture: the conductor uses a symbolic gesture that could also be understood by people who are not musicians, or have never been in an orchestra or choir, 
because it is a symbolic gesture also used, and with the same meaning, in everyday life by laypeople. An example is Index finger over lips, generally meaning "be silent", that is used to ask for "piano";

2) specific symbolic gesture: the conductor makes a symbolic gesture that in everyday life has a certain meaning, but in conduction is used with a slightly different meaning, or a more specific one. For example, the gesture of hands, palm up, oscillating on wrist up-down in its everyday reading (Morris, 1977; Poggi, 2007) means "come here", since it encourages the Addressee to come closer to the Sender. In conduction it is used with the meaning "come on, play / sing louder";

3) direct iconic gesture: the conductor makes a gesture that imitates some movement or some other kind of change in another modality. For example, the Conductor's arms curve enlarging, that imitate a swelling body, is an iconic gesture to ask for a "crescendo": a swelling sound. This is a case of "transmodal iconicity", where an analogy is set between the enlarging o widening of a physical shape and the progressive amplification of a sound: the idea of enlarging is shifted from a tactile and visual domain to an auditory one;

4) indirect iconic gesture: the conductor performs a gesture that does not directly imitate the movement it refers to, or its transmodal analogue, but imitates some movement that by inference may recall the desired intensity. Such indirect iconicity may pass through two different kinds of movement:

a. motor attitude: the gesture imitates a movement that is usually performed when producing another movement or the resulting sound. For example, to mean "sforzato" (with effort) the conductor may suddenly clunch his fist, thus imitating the movement people do when striving in some physical action;

b. emotion expression: the gesture imitates the movements typically performed in the expression of an emotion that, when felt, induces the wanted type of motor attitude or movement. For example, hands in the shape of claws vibrating with high muscular tension work as an indication for "forte", because tension is typical of an activating emotion like anger, and anger mobilizes the energy required for playing or singing "forte".

In this last case, the relationship between the conductor's signal and the desired indication is mediated by several inferential steps, like in the following scheme:

Emotion expression (ee) triggers Emotion (E)

E (Emotion) triggers Right Technical Movement (RTM)

Right Technical Movement (RTM) produces Desired Intensity (DI)

$\rightarrow$

emotion expression (ee) is a signal of Desired Intensity (DI).

Performing the expression of a given emotion evokes the emotion, and the emotion induces the conditions for the right technical movement; thus emotion expression works as a shortcut to facilitating the technical movement; but the very fact that the facilitating movement (the emotion expression) is performed becomes a signal requesting that technical movement: the emotion expression becomes an intensity indication.

\subsection{Gestures for intensity}

As is well known in the study of gesture (Stokoe, 1978; Volterra, 1987; Kendon, 2004; Poggi, 2007) each gesture can be analysed in terms of a number of parameters: handshape, location, orientation and movement. Movement is a very complex parameter including subparameters like direction, velocity, duration, but also the "expressivity 
parameters" (Hartmann et al., 2002; Poggi, 2007; Poggi et al., 2008) of amplitude, tension, fluidity. Each gesture is defined by the values it assumes with respect to all parameters.

When singling out the gestures that convey specific indications of intensity, two cases can be distinguished:

a) GLOBAL GESTURE: in some cases the dynamic indication is conveyed by the gesture globally, that is, by the information borne altogether by its parameters of handshape, location, orientation and movement (Volterra, 1987; Poggi, 2007), also including the expressive parameters of movement - among which amplitude, tension, fluidity;

b) SINGle PARAMETER(S): sometimes it is not the whole gesture that bears the intensity indication, but only one aspect of it: for instance, it is not the whole appearance of a gesture that means "forte" but only the value "high muscular tension" within the expressivity parameter of tension.

Let us see the manual signals respectively conveying "forte", "piano", "crescendo" and "diminuendo".

From a quantitative point of view, the global gesture types for the four intensity indications are 8 for "forte", 7 for "piano", 4 for "crescendo" and 2 for "diminuendo".

For each indication, we first list the global gesture, and then its pertinent parameters.

\subsubsection{Gestures asking to play or sing "forte"}

In our corpus the gestures for "forte", ordered according to the parameter of handshape, are the following:

a) Open hand

i. $\quad$ right hand, palm up, oscillates on wrist from Musicians to Conductor, as if meaning "come on, come here, come forward"

b) Extended index finger:

i. both index fingers pushed towards musicians

c) Fist shape:

i. right hand, palm to left, pushed forward towards musicians

ii. both hands, palms to each other, pushed forward towards musicians

iii. right hand, palm up, moved forward with fluid movement towards musicians

d) Claw shape (open hand with curve fingers with high muscular tension):

i. right hand, palm up, moves towards Musicians

ii. right hand, palm to Conductor, vibrating

In one case, the hand switches from a shape to another:

a) From fist to claw

i. $\quad$ right hand in fist shape, palm up, pushed towards Musicians opens up in a claw

Within a total of 8 gesture types (each with several tokens) for "forte", four handshapes are used: open hand, hand close with extended index finger, fist, and claw (i.e. open hand with curve fingers with high muscular tension). 
1.a.: right hand open, palm up, oscillates on wrist from Musicians to Conductor

As mentioned above, among the signals used by conductors some are only used in conducting, while others are the same as those used by laypeople in everyday communication. In case 1.a., the signal by itself is very similar or even identical to one used in plain communication, while its meaning may either be the same or turn up into another meaning, which, though, can still be linked to the everyday meaning through a particular inferential path, much in the same way as when, in diachronic change, a new meaning of a word or gesture stems out of another that counts as its "originary" meaning (Poggi 2007).

This last is the case for the gesture at issue.

This gesture of open hand, palm up, oscillating on wrist up and down actually corresponds to the Italian symbolic gesture which in everyday communication means: "come on, come here, come forward": a gesture to encourage someone to come towards the Sender (Poggi, 2007).

This literal meaning of such everyday gesture can be interpreted as a request for "forte" and has certainly come to mean this in the conductor's language - thanks to two lines of inference. One is based on the very nature of encouraging: when I encourage you to do something, this means that I incite you to be corageous, brave, which entails assuring: "you are strong, don't be afraid, do dare, be determined". In other words, "don't be shy, let your music be heard aloud: play / sing forte!".

The other inferential path passes through the relationship between space and sound: the closer a sound is to your ears, the louder you hear it. Therefore, requesting "please come towards me, closer to me" implies "make your sound be heard louder".

\section{2.a. both index fingers pushed towards musicians}

This gesture, though not being a symbolic gesture, in everyday life might be interpreted as commanding in a peremptory way, by even blaming or theatening punishment to the Addressee: index fingers violently pushed forward-downward are like daggers or guns, urging the other to do something without discussing the command. The energy impressed to this movement can then be interpreted as a request for "forte".

\section{3.a. right hand in fist shape, palm to left, pushed forward towards musicians}

\section{3.b. both hands in fist shape, palms to each other, pushed forward towards musicians}

These gestures are not generally used in everyday communication, but here their energetic movement conveys a request for high intensity sound. Of course, the variant of both hand vs. one hands corresponds to a gradient of requested intensity.

\section{3.c. right hand in fist shape, palm up, moved forward with fluid movement towards}

\section{musicians}

While the former gestures imply a pushing movement with high muscular tension, here the movement is less tense. Yet, the gesture's going towards musicians and the fist shape still indicate a request for higher intensity.

\section{4.a. right hand in claw shape, palm up, moves towards musicians}




\section{4.b. right hand in claw shape, palm to conductor, vibrating}

The hand in claw shape does not only convey a request as to the parameter of intensity, but also one concerning the type of movement producing the sound: by "claw" shape I mean an open hand with fingers curved with high muscular tension, where the muscular tension of the conductor's fingers calls for tense movement in either players or singers. Consequently, this handshape does not only mean "forte", but also asks for a sound similar to one produced by a violin when strings are touched with vibrating fingers.

\section{5.a. right hand in fist shape, palm up, pushed towards Musicians opens up in a claw}

In the last gesture for "forte", the handshape shifts from "fist" to "claw", thus conveying that the sound must be "forte" but also "tense", possibly vibrating.

As it may may be clear even from some of these examples, in some cases it is not a whole gesture, with its precise shape, location, orientation and movement, that conveys the meaning of intensity, but only one of these parameters may be responsible for the meaning "play/sing forte".

For example, within the parameter of HANDSHAPE, the shape "fist" is prototypically connected with the meaning "forte". The visual metaphor (Boyes Braem, 1981) embedded in this handshape is one of a firm grasp, hence of strength, power, energy. The shape "claw" by itself incorporates the idea of a strong, possibly tense, grasp.

But also other parameters may be crucial in conveying the idea of "forte". In the parameter "DIRECTION OF MOVEMENT" of the gesture, the direction towards musicians generally by itself asks for a "forte"; and so does, sometimes, PALM ORIENTATION, with palms up always used when the dynamics is "forte", as opposed to palms down, meaning "piano".

But even more, the expressivity parameters of FLUIDITY and TENSION, along with MANNER OF MOVEMENT, are most typically the carriers of the dynamic indication "forte".

Thus, in some cases "forte" is expressed by various parameters of the gesture: like in Leonard Bernstein's rehearsal of Stravinskij's "Rite of Spring". In his foreword to the work, to provide a visual image of the dawn of the world, he evokes the dynosaurs, he reminds how heavy their steps could be, and when finally conducting, with his arms along his hips, he pushes both fists downward alternatively. This gives the image of the dynosaurs' steps, but at the same time gives the rhythm and asks for "forte", heavy and tense. And it does so by two parameters of the gesture: the fist handshape, and its jerky (low fluidity) movement, with its sudden blocked impact.

\subsubsection{Pertinent values in the gesture parameters requesting "forte"}

Actually, from some of the above examples it is clear that one parameter is the most crucial in conveying the idea of strength: the very fact that signals for "forte" can be performed with either one or two fists, whether with palm down or palm to side, or even palm up, and whatever its direction - to musicians or downward, like in Bernstein's case, all this means that the very meaning of strength is most typically conveyed by the handshape of fist.

We can therefore single out what are the values, in the parameters of gesture, including its expressivity parameters (Hartmann et al., 2002; Poggi \& Pelachaud, 2008) that are more apt to convey the dynamic indication "forte": 
- within the parameter of handshape, "forte" is most typically conveyed by fist and claw

- within the subparameters of movement and the expressivity parameters:

- direction: "forte" is conveyed by towards Musicians

- fluidity: jerky as opposed to fluid movements

o tension: high

- amplitude: wide movements (for instance, wide open arms)

- quantity of movement: high

- manner of movement: vibrating

Every time these values occur in the parameters of the conductor's gesture, his indication is a request for "forte" or it is anyway linked to one. This means that each of these aspects of body movement so to speak "naturally" convey ideas of strength and energy.

\subsubsection{Gestures for "piano"}

The whole gestures used to request "piano" are the following:

a) Open hand

i. Both hands open with close fingers, palms down, move inward-outward as if smoothing a surface

ii. Both hands open with close fingers, palms down, slightly move downward, as if keeping a surface down

iii. Both hands open with close fingers, palms forward, move forward

iv. Both hands open with slightly open fingers, palms forward, oscillate on wrist left-right

v. One or both hands open, palms down, alternatively move fingers up and down gently

b) Extended index finger:

i. Right hand, palm to left, extended index finger up, moved towards conductor's mouth, to touch lips

c) Precision grip:

i. right hand or both hands with thumb and index finger touching, palms forward move forward in a fluid manner

In these 7 gesture types for "piano", 3 handshapes are used. The extended index finger touching lips (n.7), is the symbolic gesture for "keep silent", and the precision grip, thumb and index finger touching (n.8), carries the visual metaphor of taking something with caution and delicacy. The open hand (6), instead, is used in various gestures:

6.a. Both hands open with close fingers, palms down, move inward - outward as if smoothing a flat surface

This is an iconic gesture imitating the movement of someone who is making a flat horizontal surface smoother: this carries the metaphor of something continuous, and with no abrupt change: it might mean "something that does not change", but in fact means, "a sound without any peaks of intensity". 
7.b. Both hands open with close fingers, palms down, slightly move downward, as if pushing a surface down

This is an iconic gesture too, meaning: "keep it down". Again, the gesture of preventing some surface from coming upward resembles, in a spatial domain, the act of keeping something low in the acoustic domain.

\section{6.c. Both hands open with close fingers, palms forward, move forward}

This corresponds to a symbolic gesture that means "stop there, do not come further": I ask you not to come closer, where coming closer spatially implies being heard louder: once more, the acoustic indication is implied by the spatial request.

6.d. Both hands open with slightly open fingers, palms forward, oscillate on wrist left-right specularly

This corresponds to the symbolic gesture of shaking one index fingers to mean "No": a negative request, "don't do this", here, namely, "do not sing louder". But it is a heightened form of that gesture, since it is not only one finger which is shaking, but a whole hand, and even both hands.

6.e. One or both hands open, palms down, alternatively move fingers up and down gently

This is a gesture specifically performed in conduction, and generally absent in laypeople's eveyday communication. The shape is the open hand, but fingers move as if gently playing an imaginary piano, conveying an image of a surface that moves in a gentle and nonconspicuous way, like the twinkling of a calm sea under the sun.

\subsubsection{Pertinent values in the parameters of the gestures for "piano"}

The relevant parameters calling for a reduction of musical intensity are the following:

- within the subparameters of movement:

- direction: "piano" is conveyed by downward movement

- fluidity: movements are always very fluid: hands are often rocking, almost dancing

○ tension: low

- amplitude: Iow

- quantity of movement: low

All these values in the parameters of movement are in some way related to a decrease in motoric energy, which specifically points at a decrease in acoustic energy. When low energy is exploited, there is less quantity of movement, and movements are less wide, less tense, and consequently more fluid; while as to direction, downward requires less energy than upward movement. Yet, probably the most pervasive aspect of all gestures for "piano" is movement fluidity.

It is interesting to observe that the values which characterize gestures for "forte" and "piano", respectively, are quite opposite to each other. "Forte" is conveyed by fist handshape, high muscular tension, jerky movement, high quantity of movement, upward direction, while "piano" by flat hand, low tension and high fluidity, low quantity of movement, 
downward direction. This reminds of Darwin's (1872) law of opposition, according to which opposite movements correspond to opposite emotions - or to opposite meanings.

\subsubsection{Gestures for "crescendo" and "diminuendo"}

Five gestures are used in our corpus for "crescendo", and two for "diminuendo".

In three of those for "crescendo" the exploited handshape is open hand loose, while one uses the claw.

Open hand curve loose

Arms with open hands curve open outward while shoulders raise upward

Left hand open curve loose, palm to conductor, rotates forward repeatedly in wider and wider rounds

Both arms open curve loose, palm up, alternatively move fingers up and down gently towards conductor

The first two gestures exploit the visual metaphor of something swelling; the third, like gesture 6.e above, exploits the idea of something moving (and changing) softly.

Claw shape

a. right hand in claw shape, palm down, raises upward

Here the high tension typical of the claw handshape well parallels the tension of progressively increasing intensity.

The two gestures for "diminuendo" are the following:

Open hand loose

a. left arm with open hand palm down retracts backward

$\checkmark$ shape (index and middle fingers extended open)

a. right hand in $V$ shape, palm to Conductor, moves rightward progressively closing index and middle finger

The first gesture, mainly with its parameters of movement (retraction) and direction (backward) conveys the idea that something previously higher should now decrease.

The second is an iconic gesture, but one that does not imitate the musicians' movements or the perception of their acoustic effects; it imitates the graphic symbol used in musical scores for the dynamic indication of "diminuendo": >, called "forchetta" (fork), which graphically represents something that is formerly larger and then becomes thinner; this being in its turn an imitation - through graphic means - of lowering acoustic intensity. 


\section{SIGNALS FOR INTENSIFICATION AND ATTENUATION IN OTHER MODALITIES}

Beside gestures, specific signals corresponding to the four dynamic indications can be found in other modalities. Here is a first overview, possibly to be further investigated in future works.

\subsection{Head}

In the analysed videos, the head movements to request the four dynamic indications above, are the following: "forte" is generally conveyed by an

a) energetic nod, or

b) whole head vibration.

No specific head signal for "piano" and "crescendo" results from my data, while to convey "diminuendo" the conductor

c) raises and pulls back his head, as if retracting: again an inferential link from getting farther to being heard with a lower voice.

\subsection{Face}

Facial signals for "forte" are mouth with

a) lipcorners down, or

b) pressed lips: two cases of indirect iconicity through the facial expression of the emotion of anger.

Further,

c) grin - lipcorners retracted and uncovered teeth: again indirect iconicity, but through displaying the motor attitude of effort.

\subsection{Gaze}

Gaze communicates "forte" in three ways:

a) frowning eyebrows (the emotion expression of anger);

b) wide open eyes with frowning eyebrows: a gaze conveying a performative of threat of reproach, expressing an aggressive attitude; and

c) squeezing eyes, the motor attitude of effort, to evoke energy.

Coherently with Darwin's theory of opposition, "piano" is conveyed by movements of gaze that are utterly opposite to those for "forte": typically by

a) raised eyebrows, a motor attitude evoking delicacy. Secondly by

b) half-closed eyelids, an expressive display of relaxation (Poggi et al., 2010).

Finally, sometimes "play/sing piano" is conveyed by

a) squinting eyes, possibly combined with a headshake which means "no, no, not so loud please". 
In this case the conductor's gaze mimics the expression of someone who is annoyed by too loud a sound: so it may be classified as indirect iconicity by emotion expression, but here the expressed emotion is not one to be enacted by the singer/musician, but one felt by the audience: annoyance would be the effect should musicians play/sing too loud.

Gaze n.4, raised eyebrows, is often exploited also to ask for a "diminuendo", which in fact means "progressively more 'piano'".

\subsection{Posture and body movement}

From my data, the conductor does not exploit posture to convey "forte" nor "crescendo", while he typically

a) bends forward to ask for "piano", and

b) for "diminuendo" he is somehow shrugging, closing in his shoulders, as if to look smaller: again the metaphor between space and sound.

Conversely, body movements are not used for "piano". Yet,

a) "forte" is requested by raising the quantity of movement: the conductor starts making more ample and faster movements with all his body;

b) "crescendo" is indicated by amplifying movements, while "diminuendo" by suddenly retracting backward.

\section{CONCLUSIONS}

The study presented in this work has investigated the lexical area of intensity in the multimodal communication of orchestra and choir conductors during performance, finding out 21 gesture types, and 16 types of signals by head, face, gaze, posture, and body. The recurrence of the same signals, or of the same values in their parameters in different conductors, as well as the fact that the very same type occurs without particular variations in several tokens, within the same conductor or across different ones, tells us that the signals for intensity constitute a specific lexical area within the system of musical indications, and one with specific regularities. Moreover, the analysis confirms that the semiotic devices underlying the observed signals are also recurrent and systematic.

This first overview in signals for musical intensity will be widened and deepened in two directions: on the one side, the analysis will be applied to areas concerning other aspects of musical conduction; on the other, research in the same domains will be deepened by moving from observational research to empirical studies: the hypotheses phrased about the meaning of each gesture will be tested by asking both laypeople and experts to guess the meanings of Conductors' gestures: this will allow us to understand if the supposed iconicity of some gestures may be of help to comprehension even to non-expert people, and if the lexicon of conduction is not so tightly codified as to result too specialized a language.

\section{REFERENCES}

Ashley, Richard (2000): "The pragmatics of conducting: Analyzing and interpreting conductors' expressive gestures". In C. Woods, G. Luck, R. Brochard, F. Seddon \& J. A. Sloboda (eds.), International Conference on
Music Perception and Cognition, Keele, UK, (2000).

Boyes-Braem, Penny (1981): Significant Features of the handshape in American Sign Language, 
Unpublished PhD. Thesis, University of California, Berkeley.

Caffi, Claudia (1999): "On mitigation", Journal of Pragmatics, 31, 881-909.

Darwin, Charles (1872): The Expression of the Emotions in Man and Animals, New York and London, Appleton and Company.

Ekman, Paul (1979): "About brows: Emotional and conversational signals". In M. von Cranach, K.Foppa, W. Lepenies and D.Ploog, eds., Human ethology: Claims and limits of a new discipline: contributions to the Colloquium, Cambridge, Cambridge University Press, 169248.

Ekman, Paul and Wallace Friesen (1969): "The repertoire of nonverbal Behavior: Categories, origins, usage and coding", Semiotica 1, 1, 4998.

Gili Fivela, Barbara and Carla Bazzanella (2009): Fenomeni di intensità dell'italiano parlato, Firenze, Franco Cesati Editore.

Hartmann, Björn, Maurizio Mancini and Catherine Pelachaud (2002): "Formational Parameters and Adaptive Prototype Instantiation for MPEG-4 Compliant Gesture Synthesis", Computer Animation 2002, 111-119.

Kendon, Adam (1988): Sign Languages of Aboriginal Australia. Cultural, semiotic, and communicative perspectives, Cambridge, Cambridge University Press.

Kendon, Adam (2002): "Some uses of the head shake", Gesture 2,2 (2002), 147-182.

Kendon, Adam (2004): Gesture. Visible action as utterance, Cambridge, Cambridge University Press.

Poggi, Isabella (2006): "Body and mind in the Pianist's performance". In Mario Baroni, Maria Rita Addessi, Roberto Caterina and Marco Costa, eds., Proceedings of the 9th International Conference on Music Perception and Cognition, ICMPC, Bologna, 22-26 August, 2006, 1044-1051.
Poggi, Isabella (2007): Mind, hands, face and body. A goal and belief view of multimodal communication, Berlin, Weidler.

Poggi, Isabella (2011): "Music and leadership: the Choir Conductor's multimodal communication". In Miro Ichino and Gale Stam, eds., Integrating Gestures. The interdisciplinary nature of gestures, Amsterdam, John Benjamins, 341-353.

Poggi Isabella, Francesca D'Errico and Alessia Spagnolo A. (2010): "The Embodied Morphemes of Gaze", in Stephan Kopp, Ipke Wachsmuth (eds.), Gesture Workshop 2009, LNAI 5934, Berlin Heidelberg, Springer-Verlag, 34-46.

Poggi, Isabella and Catherine Pelachaud (2008): "Persuasion and the expressivity of gestures in humans and machines", in Ipke Wachsmuth, Manuela Lenzen, Günther Knöblich (eds.), Embodied Communication in Humans and Machines, Oxford, Oxford University Press, 391-424.

Stokoe, William C. (1978): Sign Language Structure: An Outline of the Communicative Systems of the American Deaf, Silver Spring, Linstock Press.

Vincze, Laura, Isabella Poggi and Francesca D'Errico, (2012): "Vagueness and dreams. Analysis of body signals in vague dream telling", in Albert Ali Salah, J.R-del-Solar, Ç. Meriçli, P.Y Oudeyer (eds.), Human Behaviour Understanding for Robotics. Lecture Notes in Computer Science, Vol. 7559, 2012, 77-89.

Vincze, Laura and Isabella Poggi (submitted): "I am really certain of this! Towards a multimodal repertoire of signals communicating a high degree of certainty", in P.Paggio, C.Navarretta, J.Allwood, E.Ahlsèn, K.Jokinen (eds.) Proceedings of the MMSYM (MultiModal Symposium) 2016, Copenhagen, September 29-30, 2016.

Volterra, Virginia. (1987): LIS. La Lingua Italiana dei Segni, Bologna, II Mulino 